\title{
Letter to the Editor: Safety and Efficacy of Bedside Peritoneal Dialysis Catheter Placement in the COVID-19 Era: Initial Experience at a New York City Hospital
}

\author{
Venice Chávez Valencia ${ }^{1} \cdot$ Francisco Alejandro Lagunas Rangel $^{2} \cdot$ Citlalli Orizaga de la Cruz $^{1}$
}

Published online: 9 July 2020

(C) Société Internationale de Chirurgie 2020

We read with interest the article by Vigiola-Cruz et al. [1] and we would like to offer the following comments.

First, acute renal replacement therapy (RRT), when required for acute kidney injury (AKI), can be administered in three different forms: continuous RRT, intermittent RRT, intermittent hemodialysis or slow extended dialysis, and peritoneal dialysis (PD). Several studies have reported satisfactory performance and outcomes with PD [2]. In this context, dialysis in patients with COVID-19 and AKI was required up to $9 \%$ [3], where the indication to start renal replacement is managed according to international guidelines. In this pathology, renal replacement is very useful given the large number of factors that are aggressive to the kidney, where hemodialysis has been the main form of replacement therapy, but DP may be a safe alternative with catheter placement in the bedside of the patients.

Second, COVID-19 has been isolated from different samples (blood, oropharyngeal swabs, urine, feces, etc.), but not from the peritoneal effluent. Wang W. et al. [4] showed in 1070 samples collected from 205 patients with COVID-19 that bronchoalveolar lavage fluid samples had higher positive rates (93\%), followed by sputum (72\%), nasal swabs (63\%), fibrobronchoscope brush biopsy (46\%), pharyngeal swabs $(32 \%)$, feces $(29 \%)$, and blood $(1 \%)$. However, it is important to remember the viral loads

Venice Chávez Valencia

drvenicechv@yahoo.com.mx

1 Department of Nephrology. Hospital General Regional Hospital No. 1, Instituto Mexicano del Seguro Social, Bosques de los Olivos No.101. Av. La Goleta Mpo Charo, Morelia, Michoacán, Mexico

2 Department of Genetics and Molecular Biology, Centro de Investigación Y de Estudios Avanzados del Instituto Politécnico Nacional (CINVESTAV), Mexico City, Mexico detected in patients with hepatitis B and C, and the infectivity of the peritoneal effluent. Cusumano AM. et al. [5] reported that the hepatitis $\mathrm{C}$ virus (HCV) crosses the peritoneal membrane and can be detected in the dialysate of PD patients with proven viremia.

Third, although it is true that the recommended personal protection equipment was used for the placement of the catheter, what is the potential risk of infectivity due to the viral load in the effluent?; what is the potential risk of infection in the medical staff?; what is the intra-abdominal pressure?; and, how do ventilatory parameters behave in patients with and without receiving pronation therapy and PD?

The final point is that while this still seems unknown or under study, we need to ask ourselves and design new studies to answer these questions, given the great opportunity offered by peritoneal dialysis for those areas where hemodialysis is difficult to access due to both the economic problem and its availability.

Authors' contributions All authors had access to the data and participated in writing the manuscript.

Funding This research did not receive any specific Grant from funding agencies in the public, commercial, or not-for-profit sectors.

Compliance with ethical standards

Conflict of interest All authors declare that they have no conflict of interest. 


\section{References}

1. Vigiola Cruz M, Bellorin O, Srivatana V, Afaneh C (2020) Safety and efficacy of bedside peritoneal dialysis catheter placement in the COVID-19 era: initial experience at a new york city hospital. World J Surg. https://doi.org/10.1007/s00268-020-05600-4

2. Ronco C, Bellomo R, Kellum JA (2019) Acute kidney injury. Lancet 394(10212):1949-1964. https://doi.org/10.1016/S01406736(19)32563-2

3. Chen N, Zhou M, Dong X, Qu J, Gong F, Han Y et al (2020) Epidemiological and clinical characteristics of 99 cases of 2019 novel coronavirus pneumonia in Wuhan, China: a descriptive study. Lancet 395(10223):507-513. https://doi.org/10.1016/ S0140-6736(20)30211-7(Epub 2020 Jan 30)

4. Wang W, Xu Y, Gao R, Lu R, Han K, Wu G, Tan W (2020) Detection of SARS-CoV-2 in different types of clinical specimens. JAMA. https://doi.org/10.1001/jama.2020.3786

5. Cusumano AM, Poratto F, del Pino N, Fernández JL, Vilches A (2005) Identification of hepatitis C virus RNA in peritoneal dialysis fluid of patients with viremia. Perit Dial Int 25(5):478-482

Publisher's Note Springer Nature remains neutral with regard to jurisdictional claims in published maps and institutional affiliations. 